\title{
Degradation Mechanism of the Biomedical Mg-3Zn-0.5Zr Alloy in a Simulated Physiological Environment Containing Different Anions
}

\author{
Sun Shizhao1, $\quad$ Bi Yanze1, $\quad$ Chen Minfang1, $\quad$ Liu Debao', $\quad$ You Chen ${ }^{1}, \quad$ Huang Yan ${ }^{2}$ \\ ${ }^{1}$ Key Laboratory of Display Materials and Photoelectric Device (Ministry of Education), Tianjin University of Technology, Tianjin 300384, China; \\ ${ }^{2}$ BCAST, Brunel University, Uxbridge, Middlesex, UB83PH, UK
}

\begin{abstract}
The interaction and synergetic effects of four corrosive anions $\left(\mathrm{Cl}^{-}, \mathrm{HPO}_{4}{ }^{2-}, \mathrm{HCO}_{3}{ }^{-}\right.$, and $\left.\mathrm{SO}_{4}{ }^{2-}\right)$ on the degradation behavior of a Mg-3wt\%Zn-0.5wt\%Zr (Mg-3Zn-0.5Zr) alloy were investigated using electrochemical tests, such as potentiodynamic polarization, open circuit potential evolution, and electrochemical impedance spectroscopy (EIS). We find that chloride ions induce porous pitting corrosion on the alloy. The corrosion pits expand on the surface and become much deeper. Hydrogen phosphate ions decrease the degradation rate and restrain the pitting corrosion. However, the degradation rate of the $\mathrm{Mg}-3 \mathrm{Zn}-0.5 \mathrm{Zr}$ alloy is accelerated at early time points during immersion in solutions containing hydrogen carbonate ions; never the less, precipitation of the magnesium carbonate results in passivation, and the corrosion products totally inhibit the pitting corrosion. In addition sulfate ions could also corrode the $\mathrm{Mg}-3 \mathrm{Zn}-0.5 \mathrm{Zr}$ alloy; due to its low concentration in the physiological environment, however, the effects of sulfate on the degradation rate and corrosion morphology are limited.
\end{abstract}

Key words: $\mathrm{Mg}-3 \mathrm{Zn}-0.5 \mathrm{Zr}$ alloy; biomaterial; corrosive anions; degradation mechanism

As a potential biodegradable material, magnesium alloys have received increasing research attention in recent years due to their desirable mechanical properties and good biocompatibility. However, the poor corrosion resistance of magnesium and its alloys restrict their application. In addition, pure magnesium and its alloys corrode too quickly in the physiological environment, as well as in solutions containing the same aggressive ions as human body fluids ${ }^{[1]}$. These aggressive ions, such as chlorides, hydrogen phosphates, hydrogen carbonates, and sulfates, are generally considered to be the reason for the fast degradation rates of pure magnesium and its alloys.

The influence of aggressive ions on the degradation rate of commercial magnesium alloys has been studied ${ }^{[2]}$. For instance, the corrosive behavior of $\mathrm{Mg}$ alloys in solutions that contain chloride ions has been investigated ${ }^{[3]}$. Chloride ions can transform the protective corrosion products $\mathrm{MgO}$ and
$\mathrm{Mg}(\mathrm{OH})_{2}$ into soluble $\mathrm{MgCl}_{2}{ }^{[4]}$.

In the present work, we prepared $\mathrm{Mg}-3 \mathrm{wt} \% \mathrm{Zn}-0.5 \mathrm{wt} \% \mathrm{Zr}$ $(\mathrm{Mg}-3 \mathrm{Zn}-0.5 \mathrm{Zr})$ alloy as the test material. In our previous research $^{[5]}$, we found that this alloy displays better biocompatibility and proper mechanical properties. Research on the degradation behavior of $\mathrm{Mg}-3 \mathrm{Zn}-0.5 \mathrm{Zr}$ alloy in Simulated Body Fluid (SBF) indicates that the degradation rate is fast. However, the synergistic effect and mutual influence of aggressive anions on the degradation of $\mathrm{Mg}-3 \mathrm{Zn}-0.5 \mathrm{Zr}$ alloy has not been understood. Thus, investigation of the influence of aggressive anions on this $\mathrm{Mg}$ alloy may offer more information about the corrosion mechanism and may reveal appropriate ways to improve the corrosion resistance of the alloy.

Four solutions containing different corrosive ions (chloride ions, hydrogen phosphate ions, hydrogen carbonate ions, and sulfate ions) with concentrations as that of the human body fluids were designed to test the degradation behavior of the

Received date: November 11,2015

Foundation item: National Natural Science Foundation of China (51371126); Science and Technology Supporting Program in Tianjin (14ZCZDGX00007); International Exchange-NSFC-RS (5131113013); Self-Create Program of Science and Technology Plan in Tianjin Binhai New Area (2012-BK120024)

Corresponding author: Chen Minfang, Professor, School of Materials Science and Engineering, Tianjin University of Technology, Tianjin 300384, P. R. China, Tel: 0086-22-60215845, E-mail: mfchentj@ 126.com 
$\mathrm{Mg}-3 \mathrm{Zn}-0.5 \mathrm{Zr}$ alloy. Our results may provide knowledge on the degradation mechanism of $\mathrm{Mg}-3 \mathrm{Zn}-0.5 \mathrm{Zr}$ alloy in a physiological environment.

\section{Experiment}

Samples with a size of $\Phi 8 \mathrm{~mm} \times 3 \mathrm{~mm}$ were cut from the extruded and aged bars of $\mathrm{Mg}-3 \mathrm{Zn}-0.5 \mathrm{Zr}$ alloy that was prepared in a vacuum induction melting furnace. The four types of solutions were prepared with $\mathrm{NaCl}, \mathrm{K}_{2} \mathrm{HPO}_{4} \cdot 3 \mathrm{H}_{2} \mathrm{O}$, $\mathrm{NaHCO}_{3}$, and $\mathrm{Na}_{2} \mathrm{SO}_{4}$, which were denoted as solution 1\#, 2\#, $3 \#$ and 4\#, respectively. The concentration of the $\mathrm{Cl}^{-}, \mathrm{HPO}_{4}{ }^{2-}$, $\mathrm{HCO}_{3}{ }^{-}$, and $\mathrm{SO}_{4}{ }^{2-}$ in the four solutions simulated that in human body fluids ${ }^{[2]}$.

The immersion tests were performed in four solutions at $37{ }^{\circ} \mathrm{C}$ without de-aeration using an immersion oscillator according to ASTM-G13-72. The samples were removed from the solutions, after different immersion periods ( $30 \mathrm{~min}$ to $7 \mathrm{~d}$ ). The $\mathrm{pH}$ values of the four test solutions at different immersion periods (30 $\mathrm{min}$ to $7 \mathrm{~d}$ ) were tested after samples were removed from the solutions at $37^{\circ} \mathrm{C}$. Field emission scanning electron microscopy (FE-SEM, JOEL6700F, Japan) was used to characterize the surface morphology of the samples after immersion for $7 \mathrm{~d}$. Glancing angle X-ray diffraction (GAXRD) was employed to identify the corrosion products on the samples after immersion for $7 \mathrm{~d}$. Subsequently, the corrosion rates were calculated by mass loss according to the equation:

$C R=\left(w_{0}-w_{1}\right) /(A t)$

The electrochemical corrosion behavior of the Mg-3Zn$0.5 \mathrm{Zr}$ alloy was investigated in the four test solutions using potentiodynamic polarization tests, open circuit potential evolution $\left(E_{\text {corr }} t\right)$, and EIS using Zennium (Germany) ${ }^{[6]}$.

\section{Results and Discussion}

\subsection{Corrosion products and morphology}

Fig. 1 shows the XRD patterns of the $\mathrm{Mg}-3 \mathrm{Zn}-0.5 \mathrm{Zr}$ alloy immersed in the four anion solutions for $7 \mathrm{~d}$. Based on the XRD pattern of the Mg alloy immersed in solution 1\# (Fig.1a), we observed the narrow and high intensity peaks of $\mathrm{Mg}(\mathrm{OH})_{2}$, which reveal the high crystallinity of the corrosion product.

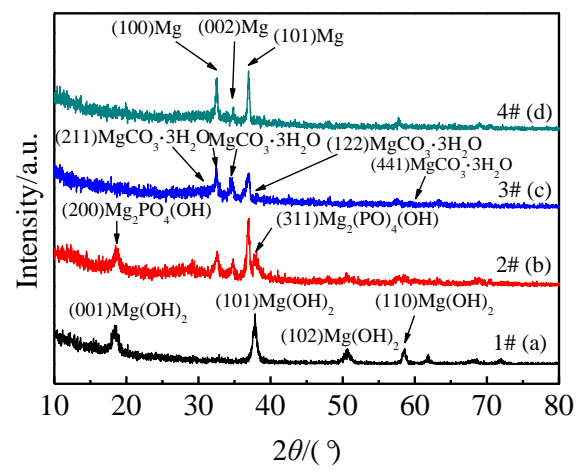

Fig.1 XRD patterns of the Mg-3Zn-0.5Zr alloy after immersion in the four test solutions for 7 days
In Fig.1b, diffraction peaks of $\mathrm{Mg}_{2} \mathrm{PO}_{4}(\mathrm{OH})$ appear at $18.6^{\circ}$ and $36.98^{\circ}$. Meanwhile, the $\mathrm{Mg}(\mathrm{OH})_{2}$ still exists on the surface of the samples, with very little decrease in $\mathrm{Mg}(\mathrm{OH})_{2}$ peak intensity, indicating that only a small amount of $\mathrm{Mg}(\mathrm{OH})_{2}$ is substituted for $\mathrm{Mg}_{2} \mathrm{PO}_{4}(\mathrm{OH})$. The corrosion products of the alloy immersed in solution 2\# are composed of $\mathrm{Mg}(\mathrm{OH})_{2}$ and $\mathrm{Mg}_{2} \mathrm{PO}_{4}(\mathrm{OH})$. The corrosion products change significantly in solution 3\# (Fig.1c). The diffraction intensity of the $\operatorname{Mg}(\mathrm{OH})_{2}$ is much lower, but the diffraction peaks of $\mathrm{MgCO}_{3} \cdot 3 \mathrm{H}_{2} \mathrm{O}$ are present at $30.1^{\circ}$ and $38.1^{\circ}$. This indicates that the $\mathrm{HCO}_{3}{ }^{-}$has a large effect on the corrosion behavior of the alloy. $\mathrm{Mg}(\mathrm{OH})_{2}$ and $\mathrm{MgCO}_{3} \cdot 3 \mathrm{H}_{2} \mathrm{O}$ are the main components of the corrosion layer. The XRD pattern of the sample immersed in solution 4\# (Fig.1d) is similar to that of solution $3 \#$ for the concentration of $\mathrm{SO}_{4}{ }^{2-}$ is quite low in solution $4 \#$.

The surface morphology of the Mg-3Zn-0.5Zr alloy soaked in the four test solutions displays significant differences in different solutions depending on the immersion time. After immersion for $12 \mathrm{~h}$, many corrosion pits are found on the surface of samples in solution 1\#, where non-uniform corrosion apparently occurs (Fig.2a). The corrosion pitting is observed at fewer locations, and the surface of the alloy remains flat in solution 2\# (Fig.2b), indicating that the corrosion is less serious than samples incubated in solution $1 \#$. As shown in Fig.2c and 2d, the corrosive pitting is not obvious on the surface of the alloy. Some cracks are clearly visible in Fig.2c and 2d, but these cracks may be attributed to the dehydration of the corrosion products in the corrosion layer. With increasing of the soaking time, the corrosion pits in solutions $1 \#$ and 2\# increase in depth after $2 \mathrm{~d}$ (Fig.3a and 3b). Many serious corrosion pits are observed in the macroscopic figures, and many corrosion pits merge together in solution 1\# On the contrary, the corrosion layers of samples in solutions $3 \#$ and $4 \#$ are dense and uniform. Fig.4 presents the corrosion morphology of the alloy after immersion in the solutions for 7 d. Although the corrosion products also peel off from the samples immersed in solutions $3 \#$ and $4 \#$, the corrosion in these solutions is uniform without serious corrosion pits ${ }^{[7]}$.

With the degradation of the $\mathrm{Mg}-3 \mathrm{Zn}-0.5 \mathrm{Zr}$ alloy, $\mathrm{OH}^{-}$ promotes the precipitation of $\mathrm{Mg}(\mathrm{OH})_{2}$, and thus, the $\mathrm{Mg}(\mathrm{OH})_{2}$ layer is too loose to provide enough protection. The $\mathrm{Cl}^{-}$in solutions can react with $\mathrm{Mg}(\mathrm{OH})_{2}$ to form the soluble $\mathrm{MgCl}_{2}$, and this reaction accelerates the degradation rate of the alloy $^{[8]}$. The propagation and spread of the pits lead to porous corrosion morphology (Fig.4a). The early corrosion product of the alloy immersed in solution 2\#, i.e., the insoluble $\mathrm{Mg}_{2} \mathrm{PO}_{4^{-}}$ $(\mathrm{OH})$, partially protects the alloy. Due to the low content of $\mathrm{HPO}_{4}{ }^{3-}$, the product layer could not completely prevent the alloy from pitting (Fig.4b). However, no porous pitting corrosion is visually observed on the entire surface of the samples soaked in solutions $3 \#$ and $4 \#$. The degradation of the alloy results in increasing $\mathrm{pH}$. The existence of $\mathrm{HCO}_{3}{ }^{-}$enables 


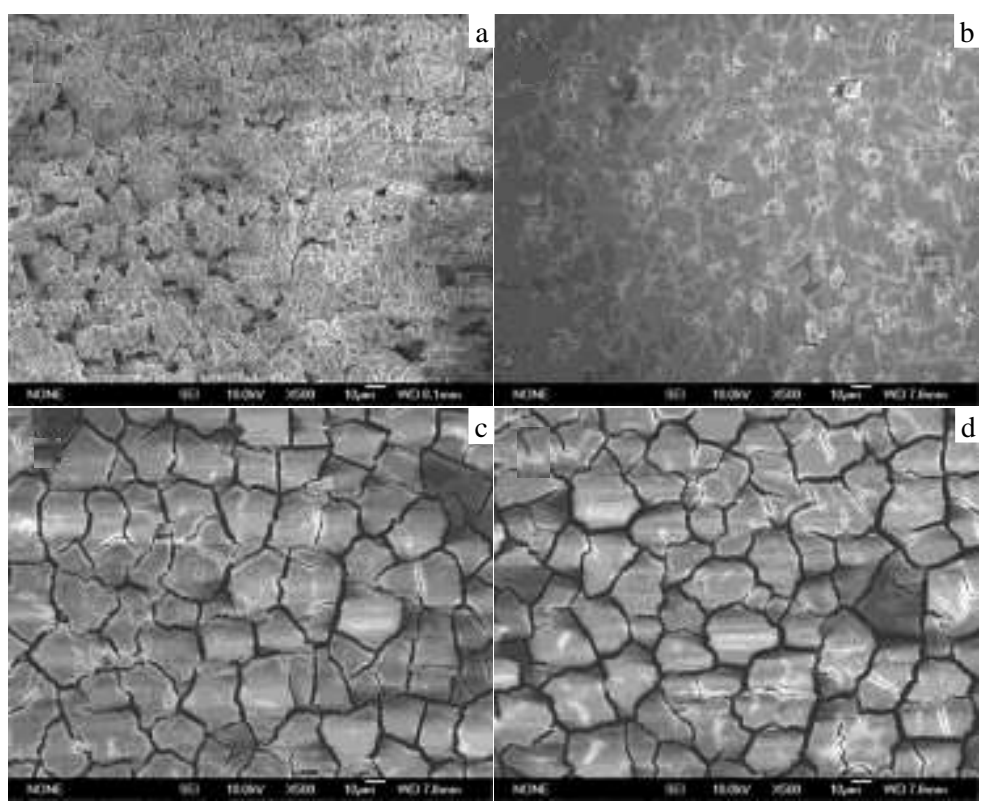

Fig.2 Corrosion morphologies of the Mg-3Zn-0.5Zr alloy after immersion in the four test solutions for $12 \mathrm{~h}$ : (a) 1\#, (b) 2\#, (c) 3\#, and (d) 4\#

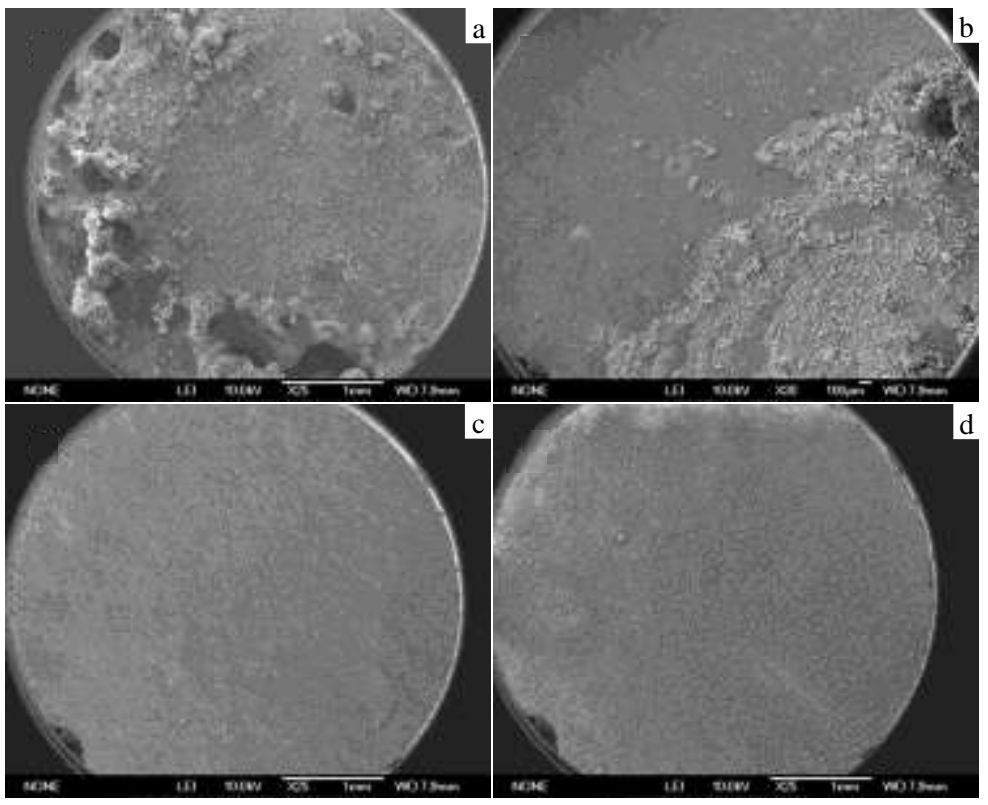

Fig.3 Corrosion morphologies of the Mg-3Zn-0.5Zr alloy after immersion in the four test solutions for $2 \mathrm{~d}$ : (a) 1\#, (b) 2\#, (c) 3\#, and (d) 4\#

the reaction between $\mathrm{Mg}^{2+}$ and $\mathrm{CO}_{3}{ }^{2-}$ when the $\mathrm{pH}$ value reaches $9.3^{[9]}$. The insoluble $\mathrm{MgCO}_{3}$ may offer excellent protection, which can strongly suppress pitting corrosion on the sample surface.

\subsection{Degradation tests}

The mass loss and degradation rates are shown in Fig.5 and 6 , respectively. The mass loss of samples in the four solutions is similar during the first $24 \mathrm{~h}$. However, after continued immersion for the next $24 \mathrm{~h}$, the mass loss of the samples in solutions $1 \#$ and $2 \#$ is greater than that in solutions $3 \#$ and $4 \#$. Particularly in solution $1 \#$, the existence of $\mathrm{Cl}^{-}$ions has an impact on the degradation rate. The mass loss of samples in solution $1 \#$ is much greater than that of the other three solutions at each time point. The mass loss in solutions 2\#, 3\#, and $4 \#$ at the subsequent time points after $24 \mathrm{~h}$ remains relatively close, indicating that $\mathrm{HPO}_{4}{ }^{3-}$ and $\mathrm{HCO}_{3}{ }^{-}$affect degradation. The dissolution product of the $\mathrm{Mg}$ alloy is $\mathrm{OH}^{-}$, which increases the $\mathrm{pH}$ of the medium. As shown in Fig.7, the $\mathrm{pH}$ in solutions $1 \#$ and $2 \#$ is higher than that in $3 \#$ and $4 \#$ because the $\mathrm{HCO}_{3}^{-}$reacts with the $\mathrm{OH}^{-}$. With the increasing immersion time, the thickness of the corrosion product layer increases, and the corrosion rate gradually decreases. According 


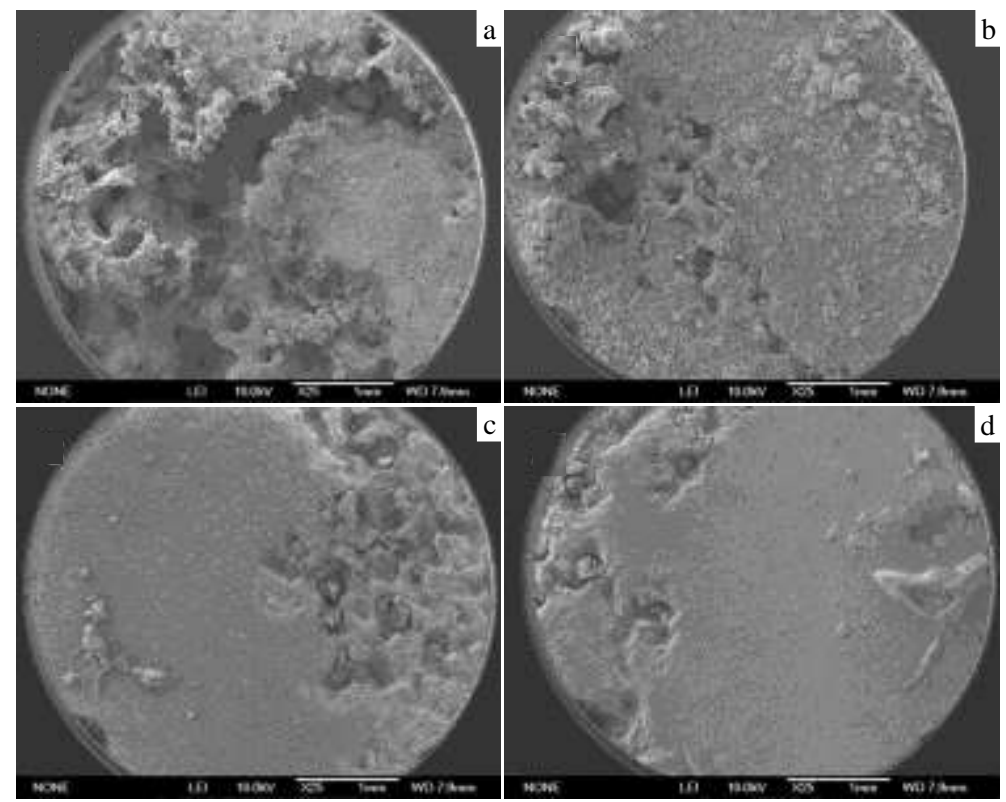

Fig.4 Corrosion morphologies of the Mg-3Zn-0.5Zr alloy after immersion in the four test solutions for $7 \mathrm{~d}$ : (a) 1\#, (b) 2\#, (c) 3\#, and (d) 4\#

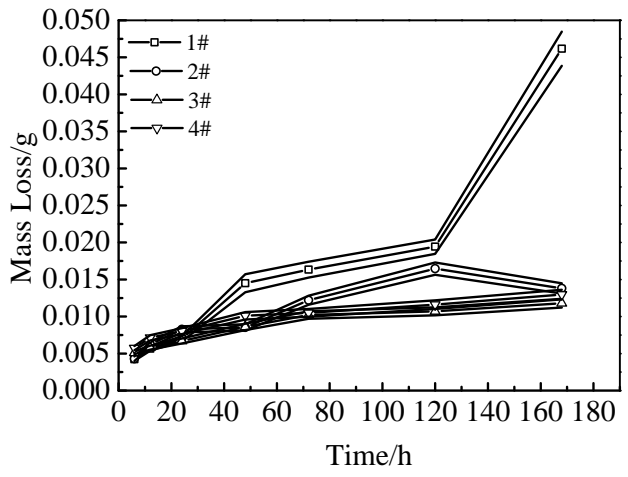

Fig.5 Mss loss of the Mg-3Zn- $0.5 \mathrm{Zr}$ alloy immersed in the four test solutions over $7 \mathrm{~d}$

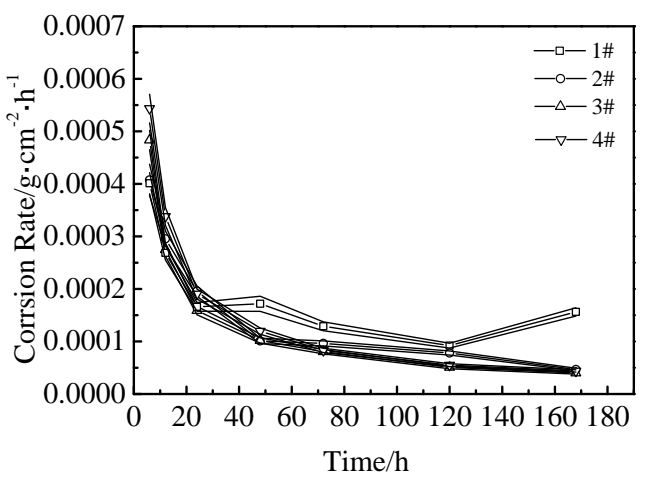

Fig.6 Degradation rate of the $\mathrm{Mg}-3 \mathrm{Zn}-0.5 \mathrm{Zr}$ alloy immersed in the four test solutions over $7 \mathrm{~d}$

to the above facts, the degradation rate in solution $1 \#$ is stable after a long immersion time. The reaction product in solution $2 \#$ is the insoluble magnesium phosphate, which makes the corrosion layer compact, inherently dense, and unaffected by chloride ions ${ }^{[10]}$. Therefore, after immersion in solution $2 \#$ for $24 \mathrm{~h}$, the degradation rate of the alloy is lower than that in solution 1\#. With the hydrogen phosphate ions, the consumption of the hydroxide ions by hydrogen carbonate ions accelerate the degradation rate of the alloy. Obviously, the corrosion rates of the $\mathrm{Mg}$ alloy in solutions 3\# and 4\# at early time points are greater than those in solutions $1 \#$ and $2 \#$. The stable $\mathrm{MgCO}_{3}$ and $\mathrm{Mg}_{3}\left(\mathrm{PO}_{4}\right)_{2}$ offer better protection, so lower corrosion rates are observed in solutions $3 \#$ and $4 \#$ compared to solutions $1 \#$ and $2 \#$ after $48 \mathrm{~h}$.

\subsection{Electrochemical results}

Typical potentiodynamic polarization curves obtained from samples immerse in the four solutions are displayed in Fig.8. The Tafel fit was used to analyze the potentiodynamic polarization curves. Comparing the corrosion potentials in solutions $3 \#$ and $4 \#$, the values increase by approximately 200 $\mathrm{mV}$ in solutions $1 \#$ and $2 \#$. The corrosion current densities

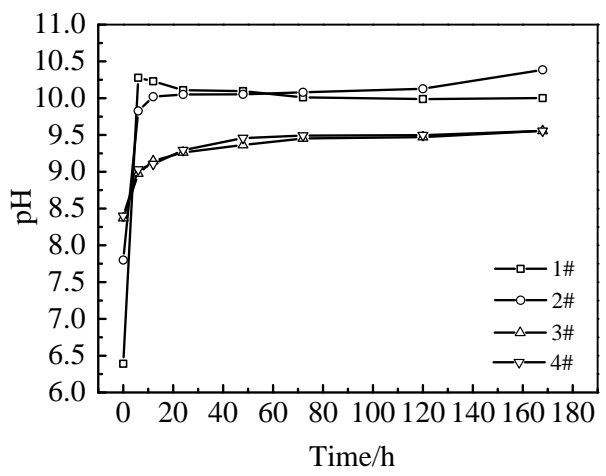

Fig.7 $\mathrm{pH}$ of the four test solutions in which the $\mathrm{Mg}-3 \mathrm{Zn}-0.5 \mathrm{Zr}$ alloy was immersed for $7 \mathrm{~d}$ 


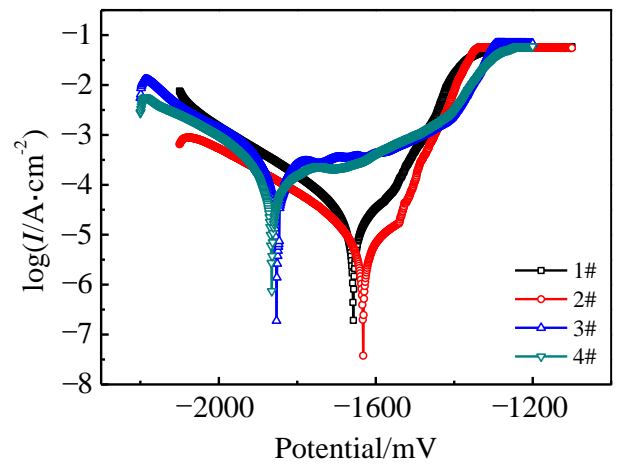

Fig.8 Representative potentiodynamic polarization curves of $\mathrm{Mg}-3 \mathrm{Zn}-0.5 \mathrm{Zr}$ alloy soaked in the four test solutions

in solutions $3 \#$ and $4 \#$ are greater than in solutions $1 \#$ and $2 \#$. Furthermore, a passivation region appears in the curves obtained from the samples immersed in solution $3 \#$ and $4 \#$ (denoted with an arrow, Fig.8). According to the above, $\mathrm{HCO}_{3}{ }^{-}$ accelerates the early corrosion rate, and the high concentration of $\mathrm{HCO}_{3}^{-}$also accelerates the formation rate of the $\mathrm{MgCO}_{3}$. The quick precipitation of the magnesium carbonate and magnesium phosphate on the surface results in the passivation. The spalls of the corrosion products leaves corrosion pits, exposing the active alloy to the solution; the reaction is concentrated in the spall position. However, due to the rapid passivation, the corrosion propagation is inhibited, preventing massive pitting corrosion in solutions $3 \#$ and $4 \#$.

Representative $E_{\text {corr }}-t$ curves of the Mg-3Zn- $0.5 \mathrm{Zr}$ alloy exposed to the four test solutions are shown in Fig.9. Initially, the potential of the sample rises quickly, but a sudden drop occurs within a very short time. This phenomenon may be related to the charging and discharging process of the electrical double layer on the surface ${ }^{[11]}$. Subsequently, the corrosion potential of the sample increases at a slower speed. A sharp rise in the potential occurs at $\sim 28 \mathrm{ks}$, indicating that along with the immersion time, the corrosion potential greatly fluctuates over a certain range, i.e., it is difficult for the

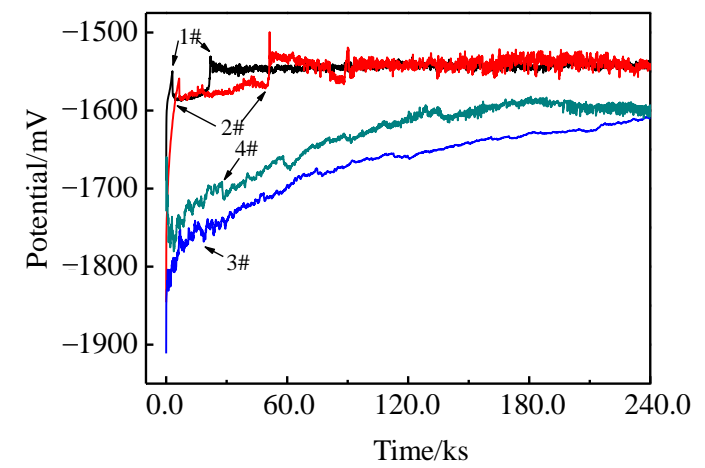

Fig.9 Open circuit potential evolution of the $\mathrm{Mg}-3 \mathrm{Zn}-0.5 \mathrm{Zr}$ alloy immersed in the four test solutions as a function of exposure time samples to reach an equilibrium state. The corrosion potential of samples in solution 2\# gradually increases at first, with sudden sharp decrease at immersion time 10, 50, and $90 \mathrm{ks}$. These results indicate the presence of the pitting points. Accompanying the degradation progress, the $\mathrm{MgZn}$ phase flakes, and the pitting occurs. Subsequently, the corrosion potential gradually increases, and the extension of pitting is suppressed. This indicates that the $\mathrm{HPO}_{4}{ }^{2-}$ ions can inhibit the extension of pitting; however the inhibition of pitting caused by $\mathrm{HPO}_{4}{ }^{2-}$ ions is very limited for its low concentration. Compared to the $E_{\mathrm{corr}}-t$ of solutions $3 \#$ and 4\#, the corrosion potential increases gradually and slowly. Although there is some slight decrease in potential, we found that the samples do not display large areas of pitting during the immersion period.

The Nyquist plots acquired from the $\mathrm{Mg}-3 \mathrm{Zn}-0.5 \mathrm{Zr}$ alloy immersed in the four test solutions for $0.5 \mathrm{~h}$ are shown in Fig.10. The Nyquist plots from the samples immersed in solutions 1\# and 2\# are the characteristic of two well-defined capacitive loops in both the high and low frequency regions. The transportation of the substance, charge transfer, and the corrosion product layer results in the two capacitive arcs. The plots obtained from samples in solutions $3 \#$ and 4\# display two capacitive loops in the high and middle frequency regions, but there is a pseudo-inductive loop in the low frequency region. The capacitive loop in the high frequency region is still caused by the electrical double layer in solutions $3 \#$ and 4\#. The capacitive loop in the low frequency region and the pseudo-inductive loop in the middle frequency region result from the charge transfer and diffusion. Therefore, the two different loops are the characteristic of two different surface states. Considering the presence of the passivation and repassivation in the potentiodynamic polarization test, these two surface states are the passive and the active regions. Fig.11 and Fig.12 show the Nyquist plots acquired from the samples immersed in the four test solutions for 6 and $24 \mathrm{~h}$, respectively. Comparing Fig.10 Fig.12, the $|Z|$ values of the samples in solutions $3 \#$ and $4 \#$ are lower than those in solutions $1 \#$ and $2 \#$ due to the presence of $\mathrm{HCO}_{3}^{-}$. After immersion in the four solutions for $6 \mathrm{~h}$, the arc diameter of the

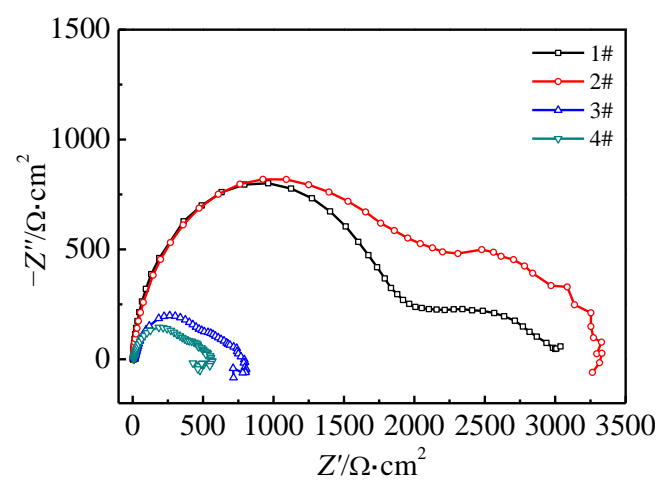

Fig.10 EIS diagram for the $\mathrm{Mg}-3 \mathrm{Zn}-0.5 \mathrm{Zr}$ alloy soaked in the four test solutions for $0.5 \mathrm{~h}$ 


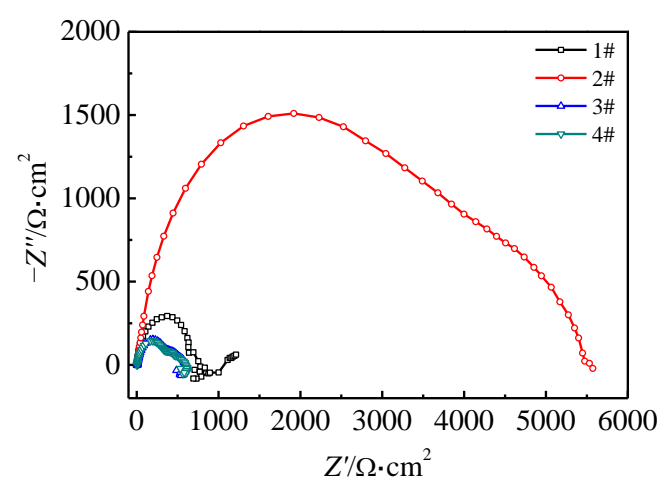

Fig.11 EIS diagram for the Mg-3Zn-0.5Zr alloy soaked in the four test solutions for $6 \mathrm{~h}$

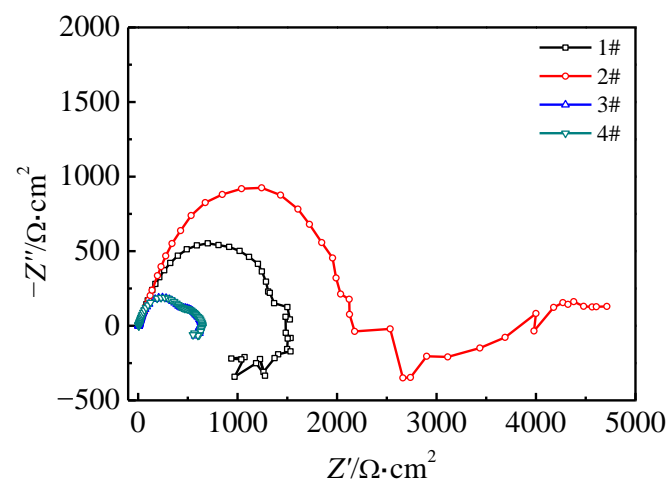

Fig.12 EIS diagram for the Mg-3Zn-0.5Zr alloy soaked in the four test solutions for $24 \mathrm{~h}$

capacitive loop in the high frequency region increases, indicating that the charge transfer is limited due to the precipitation of the corrosion products.

Considering the characteristics of the EIS results and the surface structure of the metal electrode, we diagrammed the equivalent circuit to fit the raw EIS data, as shown in Fig.13. In the diagram, $R_{\mathrm{s}}$ is the solution resistance, $C_{\mathrm{f}}$ is a constant phase element component, $R_{\mathrm{f}}$ is the corresponding layer resistance, and $Q$ is the equivalent elements (CPE). We use $Q$ to reflect the capacitive element for the appearance of dispersibility due to the non-uniformity of the electrode's surface. $n$ is the index of the $Q$, which is located between $0.5 \sim 1$, $\mathrm{m}$ is the index of the dispersion effect of the $C_{\mathrm{f}}$, which is located between $0 \sim 1$, and $R_{\mathrm{t}}$ is the charge transfer resistance, which is related to the reaction at the interface between the metal and solution. If the value of $R_{\mathrm{t}}$ increases, the resistance of the

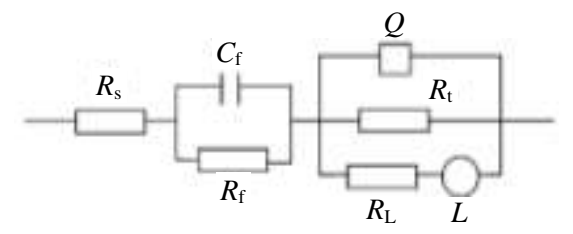

Fig.13 Equivalent circuit for the $\mathrm{Mg}-3 \mathrm{Zn}-0.5 \mathrm{Zr}$ alloy EIS tested in the four anionic solutions charge will increase, and it is more difficult for corrosion to occur. $R_{\mathrm{L}}$ is the resistance related to the inductance element $L$.

The fitting results of the EIS immersion for $0.5 \mathrm{~h}$ in the four test solutions are compiled in Table 1 . At the early immersion stage, the $R_{\mathrm{t}}$ of test in solution 1 \# is half of that in solution 2\#, but still much greater than in solutions $3 \#$ and $4 \#$. This indicates that the charge transfer resistance in solutions $3 \#$ and $4 \#$ is less than in solutions $1 \#$ and $2 \#$. The easier charge transfer, the larger corrosion tendency. Thus, the corrosion tendency in solutions $3 \#$ and $4 \#$ would be greater than in solutions $1 \#$ and 2\#. Moreover the corrosion tendency in solution $1 \#$ is greater than in solution $2 \#$, and the results are consistent with the above analysis. The presence of $\mathrm{HCO}_{3}^{-}$ greatly enhances the erosion of the sample. In addition, the $R_{\mathrm{t}}$ of solution $3 \#$ is larger than that of solution 4\#, indicating that the $\mathrm{SO}_{4}{ }^{2-}$ can accelerate the degradation rate of the alloy. In the four solutions, the $C_{\mathrm{f}}$ values are similar; the highest $C_{\mathrm{f}}$ appears in solution 2\#. Analyzing the value of $Q$ in the four solutions, it is less in solutions $1 \#$ and $2 \#$ than in $3 \#$ and $4 \#$, indicating that the corrosion is relatively uniform. There is no large-scale pitting corrosion process on the surface of the samples soaked in solutions $3 \#$ and $4 \#$. The $R_{\mathrm{f}}$ of solution $2 \#$ is significantly greater than that of other solutions. The $R_{\mathrm{f}}$ in solution $4 \#$ is the minimum, and the $R_{\mathrm{f}}$ in solutions $3 \#$ and $4 \#$ are lower than $1 \#$ and $2 \#$. The thickness of the corrosion product in solution $2 \#$ is relatively maximal, so the resistance value is maximum. The corrosion product layer of the sample immersed in solution 2\# contains large amounts of phosphate, the layer is relatively dense, and it has a certain preservative effect. Because the sample in solution 1\# only forms $\mathrm{Mg}(\mathrm{OH})_{2}$ in corrosion product layer, the chlorine ions disrupt the formation of $\mathrm{Mg}(\mathrm{OH})_{2}$. Thus, the $R_{\mathrm{f}}$ in solution 1 \# is less than in solution $2 \#$.

The fitting results of EIS immersion for 6 and $24 \mathrm{~h}$ in the four test solutions are shown in Table 2 and Table 3. According to the data in Table 2, the changes in $R_{\mathrm{t}}$ value are different in the four test solutions compared to the data of 0.5 h. There is a sharp decrease in solution $1 \#$, but the $R_{\mathrm{t}}$ in solution

Table 1 EIS fitted results of the Mg-3Zn- $0.5 \mathrm{Zr}$ alloy in the four test solutions for $0.5 \mathrm{~h}$

\begin{tabular}{ccccc}
\hline Solution & $1 \#$ & $2 \#$ & $3 \#$ & $4 \#$ \\
\hline$R_{\mathrm{s}} / \Omega \cdot \mathrm{cm}^{2}$ & 10.37 & 9.359 & 8.833 & 7.873 \\
$Q / \times 10^{-6} \Omega^{-1} \cdot \mathrm{s}^{n} \cdot \mathrm{cm}^{2}$ & 29.52 & 6.814 & 386.9 & 309.1 \\
$n$ & 0.8181 & 0.943 & 0.8 & 0.6183 \\
$R_{\mathrm{t}} / \Omega \cdot \mathrm{cm}^{2}$ & 2250 & 3418 & 536.2 & 357.5 \\
$C_{\mathrm{f}} / \times 10^{-6} \mathrm{~F} \cdot \mathrm{cm}^{-2}$ & 2.354 & 78.55 & 18.64 & 17.37 \\
$m$ & 0.856 & 0.902 & 0.612 & 0.756 \\
$R_{\mathrm{f}} / \Omega \cdot \mathrm{cm}^{2}$ & 3408 & 6248 & 260.1 & 187 \\
$R_{\mathrm{L}} / \Omega \cdot \mathrm{cm}^{2}$ & 0.08239 & 0.01 & 7385 & 957.6 \\
$L / \mathrm{F} \cdot \mathrm{cm}^{-2}$ & $3.617 \mathrm{E} 6$ & 1708 & $2.528 \mathrm{E} 4$ & 8625 \\
\hline
\end{tabular}


Table 2 EIS fitted results of the Mg-3Zn-0.5Zr alloy in the four test solutions for $6 \mathrm{~h}$

\begin{tabular}{ccccc}
\hline Solution & $1 \#$ & $2 \#$ & $3 \#$ & $4 \#$ \\
\hline$R_{\mathrm{s}} / \Omega \cdot \mathrm{cm}^{2}$ & 4.95 & 5.574 & 5.836 & 5.428 \\
$Q / \times 10^{-6} \Omega^{-1} \cdot \mathrm{s}^{n} \cdot \mathrm{cm}^{2}$ & 5895 & 17.32 & 41.41 & 38.71 \\
$n$ & 0.5798 & 0.8655 & 0.8003 & 0.8057 \\
$R_{\mathrm{t}} / \Omega \cdot \mathrm{cm}^{2}$ & 66.21 & 4055 & 418.8 & 394.3 \\
$C_{\mathrm{f}} / \times 10^{-6} \mathrm{~F} \cdot \mathrm{cm}^{-2}$ & 54.03 & 913.4 & 1619 & 1631 \\
$m$ & 0.741 & 0.859 & 0.428 & 0.809 \\
$R_{\mathrm{f}} / \Omega \cdot \mathrm{cm}^{2}$ & 658.1 & 1287 & 151.2 & 187.1 \\
$R_{\mathrm{L}} / \Omega \cdot \mathrm{cm}^{2}$ & 0.01 & 0.01 & 1221 & 701.1 \\
$L / \mathrm{F} \cdot \mathrm{cm}^{-2}$ & $1.154 \mathrm{E} 4$ & $1.003 \mathrm{E} 6$ & $1.73 \mathrm{E} 4$ & $2.465 \mathrm{E} 4$ \\
\hline
\end{tabular}

Table 3 EIS fitted results of the Mg-3Zn-0.5Zr alloy in the four test solutions for $24 \mathrm{~h}$

\begin{tabular}{ccccc}
\hline Solution & $1 \#$ & $2 \#$ & $3 \#$ & $4 \#$ \\
\hline$R_{\mathrm{s}} / \Omega \cdot \mathrm{cm}^{2}$ & 12.87 & 11.87 & 5.443 & 6.078 \\
$Q / \times 10^{-6} \Omega^{-1} \cdot \mathrm{s}^{n} \cdot \mathrm{cm}^{2}$ & 94.53 & 35.25 & 204.3 & 230.6 \\
$n$ & 0.7014 & 0.752 & 0.6502 & 0.6248 \\
$R_{\mathrm{t}} / \Omega \cdot \mathrm{cm}^{2}$ & 1001 & 3072 & 441.8 & 440.7 \\
$C_{\mathrm{f}} / \times 10^{-6} \mathrm{~F} \cdot \mathrm{cm}^{-2}$ & 47.95 & 2477 & 22.28 & 18.66 \\
$m$ & 0.549 & 0.753 & 0.882 & 0.916 \\
$R_{\mathrm{f}} / \Omega \cdot \mathrm{cm}^{2}$ & 531.8 & 1251 & 185.2 & 200.6 \\
$R_{\mathrm{L}} / \Omega \cdot \mathrm{cm}^{2}$ & 572 & 0.01 & 839 & 927.6 \\
$L / \mathrm{F} \cdot \mathrm{cm}^{-2}$ & $7.119 \mathrm{E} 4$ & $2.287 \mathrm{E} 6$ & $2.844 \mathrm{E} 4$ & $1.879 \mathrm{E} 4$ \\
\hline
\end{tabular}

2\# only partially increases. The changes in solutions $3 \#$ and $4 \#$ are not obvious. Compared to the $0.5 \mathrm{~h}$ point, the corrosion tendency of samples after soaking in solutions $3 \#$ and $4 \#$ for $6 \mathrm{~h}$ basically remains the same. The $C_{\mathrm{f}}$ values in four solutions significantly increases, indicating that the thickness of corrosion product layer increases and has an limiting effect on the corrosion. The relationship between $C_{\mathrm{f}}$ and $R_{\mathrm{f}}$ at $6 \mathrm{~h}$ is substantially consistent with that at $0.5 \mathrm{~h}$. According to the data in Table 3 , the $R_{\mathrm{t}}$ in solution $1 \#$ at $24 \mathrm{~h}$ significantly increases again. In solution $2 \#$, the $R_{\mathrm{t}}$ is slightly reduced from the $6 \mathrm{~h}$ point, and the data from solutions $3 \#$ and $4 \#$ remain similar. These results indicate that the corrosion tendency of each solution gradually decreases in solution $2 \#$ but increases in solution 1\#; the corrosion tendency in solutions $3 \#$ and $4 \#$ still maintains a relatively large tendency. The results of $R_{\mathrm{f}}$ do not significantly change in solutions \#1 and 2\#. The density of the corrosion product layer in solution $2 \#$ further improves, and significantly slows down the degradation rate over the period of 12 24 h. The $R_{\mathrm{f}}$ increases significantly in solutions
$3 \#$ and $4 \#$, but not to the extent of that in solution $1 \#$. In solutions $3 \#$ and $4 \#$, the immersion leads to the continuous deposition of stable corrosion products, the thickness and density of the corrosion product layer further improve, and the preservative effect resulting from the corrosion product layer is greater than that of solution $1 \#$.

\section{Conclusions}

The influence of the corrosive anions at concentrations similar to physiological environment on the degradation behavior of a $\mathrm{Mg}-3 \mathrm{Zn}-0.5 \mathrm{Zr}$ alloy was systematically investigated for the first time. Chloride ions induce porous pitting corrosion on the alloy; the corrosion pits both expand on the sample surface and deeper into the interior. Hydrogen phosphate ions inhibit the degradation rate and restrain the pitting corrosion. Hydrogen carbonate ions accelerate the degradation rate of the alloy at early immersion time points. However, the precipitation of magnesium carbonate results in passivation, and the corrosion products totally inhibit the pitting corrosion. Sulfate ions also corrode the alloy, but at the low sulfate concentration in the physiological environment, the effect of sulfate on the degradation rate and corrosion morphology is limited. This study provides a systematic investigation on the degradation mechanism of the $\mathrm{Mg}-3 \mathrm{Zn}-0.5 \mathrm{Zr}$ alloy and will widening its medical applications.

\section{References}

1 Witte F, Kaese V, Haferkamp H et al. Biomaterials[J], 2005, 26: 3557

2 Xin Y C, Hou K, Tao H. Acta Biomater [J], 2008, 4: 2008

3 Wang S, Pan W, Li X et al. Rare Metal Materials and Engineering[J], 2007, 36(8): 247

4 Song G L, Bowles A L, DST J. Mat Sci Eng A-Struct[J], 2004, 366: 74

5 Wang X W, Chen M F, You C et al. Rare Metal Materials and Engineering $[\mathrm{J}], 2010,39(12): 2211$ (in Chinese)

6 Ghoneim A A, Fekry A M, Ameer M A. Electrochimi Acta $[\mathrm{J}]$, 2010, 55: 6028

7 Cho S B, Nakanishi K, Kokubo T et al. J Am Ceram Soc[J], 1995, 78: 1769

8 Song G L, Andrej A. Adv Eng Mater[J], 1999, 1 : 11

9 Gao J C, Li L C, Wang Y. The Chinese Journal Nonferrous Metals[J], 2004, 14(9): 1508 (in Chinese)

10 Morks M F. Mater Lett [J], 2004, 58: 3316

11 Souza M, Lima L, Lima C et al. J Mater Sci Mater Med[J], 2009, 20: 549 


\title{
Mg-3Zn-0.5Zr 合金在含有不同离子的模拟生理环境中的降解机理
}

\author{
孙士昭 ${ }^{1}$, 毕衍泽 ${ }^{1}$, 陈民芳 ${ }^{1}$, 刘德宝 ${ }^{1}$, 由 臣 $^{1}$, 黄 岩 ${ }^{2}$ \\ (1. 天津理工大学 光电显示材料与器件重点实验室 (教育部), 天津 300384) \\ (2. BCAST, 布鲁奈尔大学, 英国, 阿克斯布里奇, 米德尔塞, UB83PH)
}

\begin{abstract}
摘 要: 采用电化学测试 (极化曲线, 开路点位, 电化学阻抗谱) 研究了 $\mathrm{Mg}-3 \mathrm{Zn}-0.5 \mathrm{Zr}$ 合金在 4 种侵蚀性离子 $\left(\mathrm{Cl}^{-}, \mathrm{HPO}_{4}{ }^{2-}, \mathrm{HCO}_{3}{ }^{-}\right.$ 和 $\mathrm{SO}_{4}{ }^{2-}$ ) 相互作用下的降解行为。发现 $\mathrm{Cl}^{-}$会导致合金发生多孔状点蚀, 腐蚀坑在表面扩展并加深。 $\mathrm{HPO}_{4}{ }^{2-}$ 能降低合金降解速率抑制点

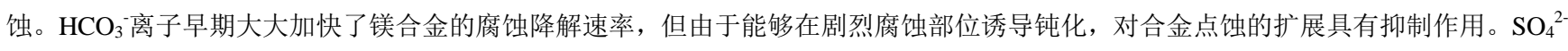
在生理环境中浓度低, 所以对合金腐蚀降解的行为加速不明显。
\end{abstract}

关键词: $\mathrm{Mg}-3 \mathrm{Zn}-0.5 \mathrm{Zr}$ 合金; 生物材料; 腐蚀性离子; 降解机理

作者简介: 孙士昭, 男, 1988 年生, 硕士, 天津理工大学材料科学与工程学院, 天津 300384, 电话: 022-60215845, E-mail: sunshizhao1010@126.com 